\title{
PROCESSOS HIDROEROSIVOS E ALTERAÇÕES FÍSICAS NO SOLO EM TRILHA DEGRADADA COMO INDICADORES DE PERTUBAÇÃO DOS SISTEMAS AMBIENTAIS EM BIOMA DE MATA ATLÂNTICA NO MUNICÍPIO DE UBATUBA-SP
}

\author{
Leonardo dos Santos Pereira ${ }^{(a)}$, Aline Muniz Rodrigues ${ }^{(a)}$, Yolanda T. Molinaro ${ }^{(a)}$, Antônio José \\ Teixeira Guerra ${ }^{(a)}$ \\ (a) Departamento de Geografia/ Instituto de Geociências, Universidade Federal do Rio de Janeiro, Email: E-mail: \\ leospgeo@gmail.com
}

\section{EIXO: SOLOS E PAISAGEM}

\begin{abstract}
Resumo
O processo de formação de trilha representa uma perturbação nos sistemas ambientais, pois está relacionado com a retirada de vegetação e pode estar associado com cortes de encostas, alterando a morfologia natural do relevo. Como reação a essa perturbação, os processos erosivos se tornam mais intensos e acelerados, uma vez que o solo se encontra exposto e as trilhas podem se tornar caminhos preferenciais para o escoamento da água. Portanto, o objetivo do trabalho é analisar o processo de degradação de uma trilha abandonada por meio do escoamento superficial em uma estação experimental de erosão de solo, relacionando com dados de chuva e hidrológicos de potenciais matriciais da água no solo. A trilha está situada na bacia do rio Maranduba, no litoral sul de Ubatuba/SP, e se apresenta dergradada, pois é constituída por solo sem cobertura vegetal, com o horizonte B exposto e elevadas taxas de perda de solo e água.
\end{abstract}

Palavras chave: Escoamento superficial; solo exposto, drenagem, potencial matricial da água no solo

\section{Introdução}

As trilhas constituem um caminho formado para o deslocamento de pessoas, em sua maioria, em ambientes de difícil acesso, sendo construídas sem adequado planejamento em ecossistemas importantes que regulam o funcionamento dos recursos ambientais. Apesar de possuir como característica espaços estreitos, podem possuir comprimentos longos que perpassam por grande parte de sistemas ambientais, logo, representam caminhos de grande abrangência, que podem repercutir em perturbações naturais (FIGUEIREDO et al., 2012).

A intensidade da atividade do fluxo de pessoas nas trilhas representa outra problemática para a ocorrência dos processos erosivos, pois quanto maior o fluxo de pessoas, maior podem ser os impactos no solo, culminando em compactação e impermeabilização do mesmo. Essa degradação intensifica ainda mais os processos erosivos e o fluxo de escoamento superficial, formando crostas no solo. Ou seja, o uso e manejo das trilhas pelas atividades humanas, como o turismo, representam riscos à sustentabilidade dos sistemas 
ambientais e, por isso, deve-se ter adequado planejamento em áreas que possuem grande atrativo de suas belezas naturais, onde a trilha é o principal meio de deslocamento (RANGEL e GUERRA, 2014; PEREIRA et al., 2016; SAFARI et al., 2016).

Kroeff (2010) ressalta como o estudo de trilhas ecoturísticas devem estar inseridas dentro do contexto geomorfológico, uma vez que podem oferecer impactos ambientais quando não são manejadas adequadamente, interferindo nas transformações da paisagem e em suas relações sistêmicas. Uma das problemáticas se alavanca, por exemplo, quando se caracteriza uma trilha, sendo vista, pela maioria, por um local de acesso estreito que são abertas para se improvisar um caminho de deslocamento. Essa visão simplista alavanca a relevância de se estudar estes ambientes, pois é através da falta de informação por parte da comunidade local e do adequado manejo que se propagam os problemas hidroerosivos, pois não observam que as trilhas pertencem a um contexto maior, estando inseridas em sistemas ambientais complexos, logo, a sua formação requer um planejamento adequado, tendo como ponto de partida a análise do relevo, solo, clima e outros elementos e variáveis ambientais (JORGE et al., 2014; SAFARI et al., 2016).

Nesta perspectiva, foi desenvolvido esse trabalho sobre trilha que a considera no contexto geomorfológico, tendo como objetivo geral a análise dos processos hidroerosivos de uma trilha abandonada e degradada, a fim de entender esses processos conjugados com a dinâmica da encosta e análises de solo. Especificamente, foi monitorado o potencial matricial da água no solo para entender a hidrologia da trilha em encosta, bem como relacionado estes dados com os de chuva e escoamento superficial. Também foi avaliado a textura do solo da trilha e se comparou com os dados de granulometrica das partículas que foram escoadas superficialmente.

\subsection{Características da área de estudo}

A área de estudo, situado no município de Ubatuba, representa um lugar de grande importância para fins de lazer e bem estar de muitos indivíduos, uma vez que está situada no litoral da região norte do estado de São Paulo (Figura 1), possuindo atrativos naturais valorosos que agregam no enriquecimento da beleza da paisagem da área. O município possui praias e cachoeiras de beleza ímpar que estão situados em Mata Atlântica e a maior parte de seu território (80\%) está inserido no Parque Estadual da Serra do Mar (PESM). Este, por sua vez, representa um ambiente de Unidade de Conservação (UC), que conjuga em seu espaço recursos ambientais importantes para o adequado funcionamento do ecossistema (BUZATO, 2012; JORGE et al., 2016). 


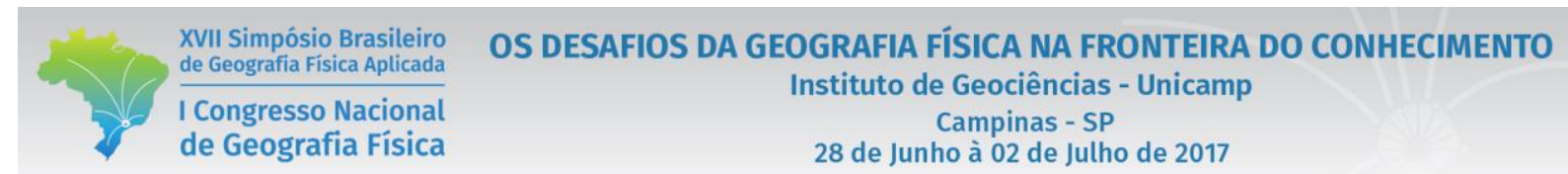

Essa beleza, portanto, tornou-se cenário almejado de descanso e lazer para milhares de turistas. Contudo, essa relação do homem com a natureza requerer um cuidado minucioso e adequado, principalmente se tratando de uma UC que está localizada em Mata Atlântica, que é o principal bioma em risco de extinção brasileiro e um dos cinco mundiais. $\mathrm{O}$ acesso às praias e cachoeiras, em muitos casos, ocorre por meio de trilhas que cortam a floresta, essas, por sua vez, não são utilizadas e manejadas adequadamente e, em muitos casos, sem controle de visitantes, ultrapassando o limite de carga que a trilha suporta do modo como foi elaborada (JORGE e GUERRA, 2016).

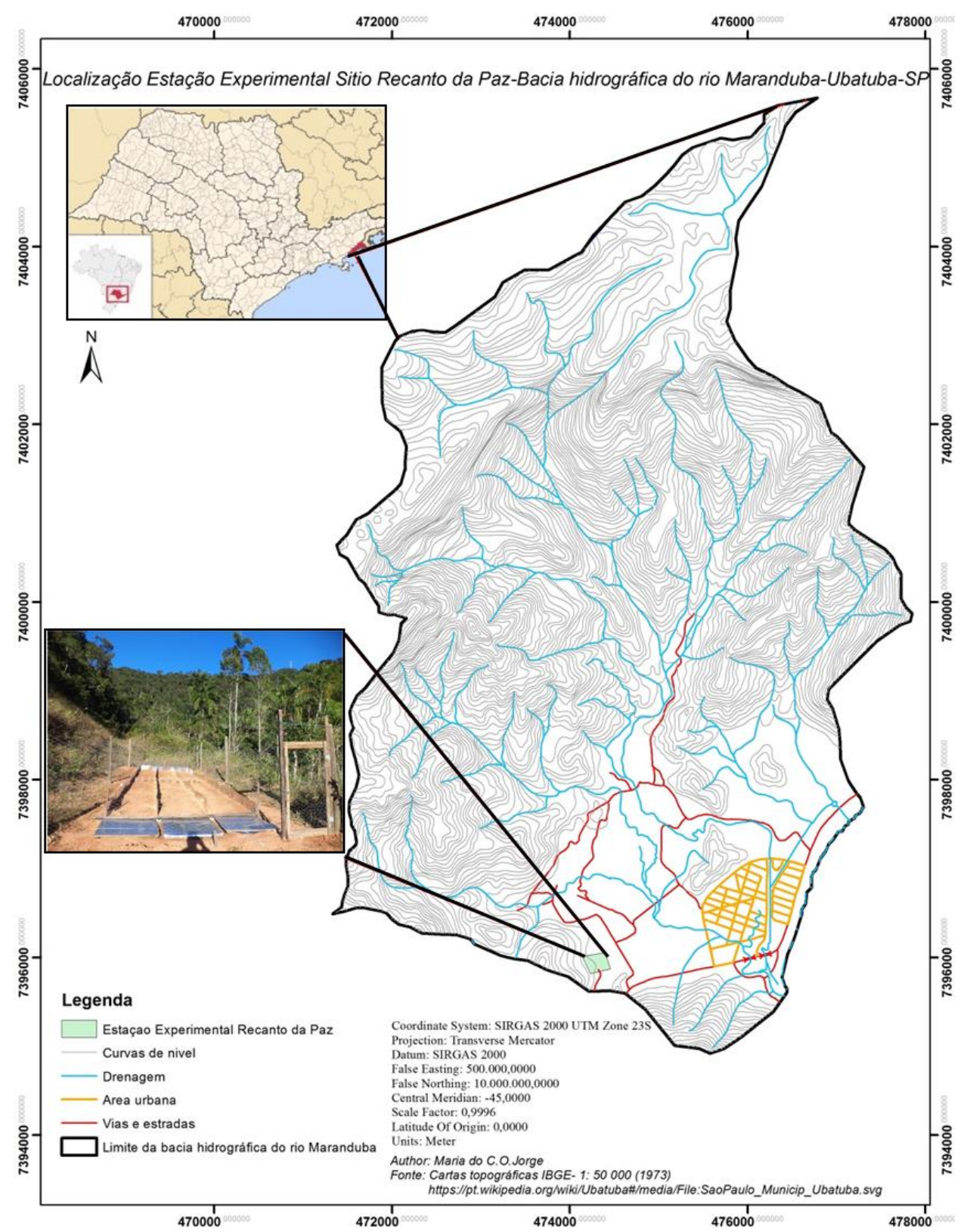

Figura 1 - Mapa de localização da área de estudo. Fonte: Pereira et al. (2016). 


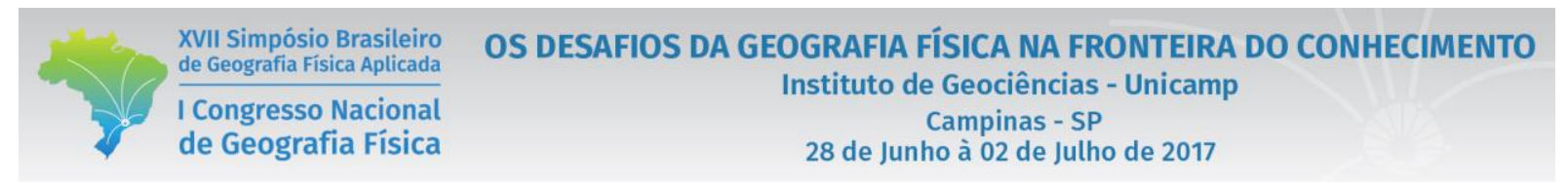

O clima de Ubatuba é caracterizado como tropical litorâneo úmido, ou tropical atlântico, com temperatura média anual de $21^{\circ} \mathrm{C}$, a temperatura média máxima chega a $27^{\circ} \mathrm{C}$ e a média mínima, de $15^{\circ} \mathrm{C}$ (FERNANDES, 2009). Ubatuba é um município que possui boa distribuição de chuva ao longo do ano, com meses mais chuvosos no verão. Segundo Nunes (2010), o município está entre as 10 mais chuvosos do Brasil, o que lhe confere grande oferta de água. Esse município também conta com constantes chuvas orográficas, isso devido ao seu território se localizar nas encostas da Serra do Mar, que recebe as massas de ar vindas do oceano, ou seja, apresenta grande densidade de massas de ar úmidas (ROSEGHINI, 2007; SANTOS \& GALVANI, 2014). Seguindo a classificação de intensidade de chuvas proposta por Reichart (1987), constata-se que 80,3\% das chuvas são leves, seguidas de $15 \%$ moderadas e $4,7 \%$ fortes (PEREIRA et al., 2015).

A estação experimental foi instalada em uma trilha situada em um morrote convexo isolado de 60 metros de altitude em uma sub-bacia do rio Maranduba. Este morrote se encontra inserido em área de planície flúvio-marinha e a morfologia original deste relevo foi modificada por meio da alteração de sua vertente, que sofreu com ações antrópicas, através da retirada de material de empréstimo de solo (Corte de encosta), culminando em uma vertente retilínea. A pedologia da área, que tem como solo característico o Latossolo, foi modificada e o horizonte A foi removido totalmente, expondo o horizonte B (Figura 2).

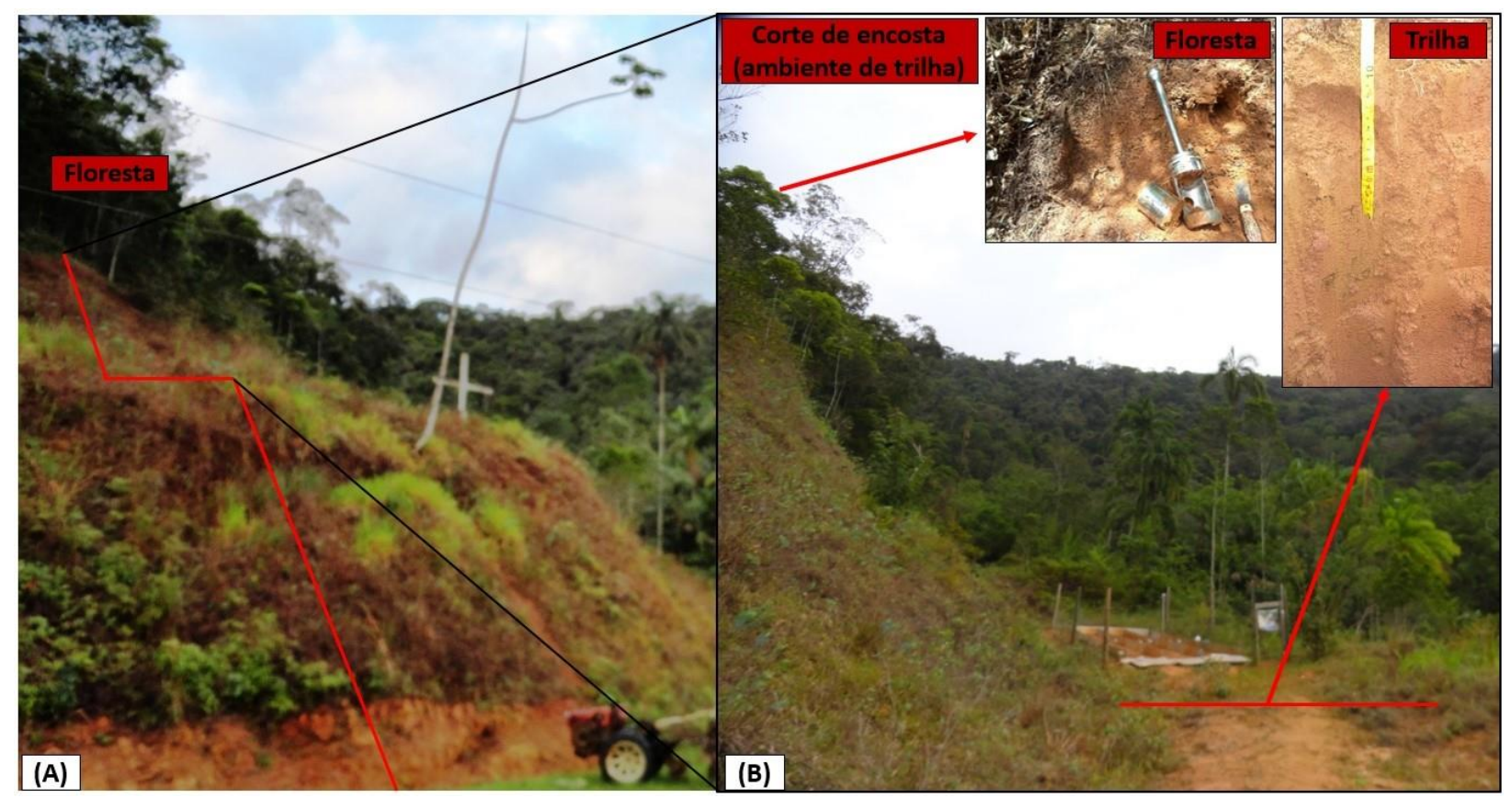

Figura 2 - Visualização geral da vertente de corte de encosta, salientando o piso da trilha onde foi elaborado o monitoramento hidrológico e de escoamento superficial. Foto: Leonardo S. Pereira, 2015. 


\section{Materiais e Métodos}

Para analisar a influência do escoamento superficial, da variação do potencial pressão negativo e de saturação, na trilha foi instalado uma estação experimental de erosão de solos com monitoramento hidrológico diário, bem como pluviométrico e de escoamento.

Para a quantificação do escomaneto superficial, três parcelas de erosão, das quais as calhas são do modelo Gerlach (GUERRA, 2005), foram instaladas em declividade de $4^{\circ}$ ao longo da largura da trilha, delimitadas com placas galvanizadas a uma profundidade de, aproximadamente, 15 a $20 \mathrm{~cm}$. As parcelas têm 10 metros de comprimento e 1 metro de largura, totalizando $10 \mathrm{~m}^{2}$ (Figura $3 \mathrm{~A}$ ), estando conectadas às calhas, que coletam os sedimentos e a caixas que armazenam o escoamento superficial. As caixas que armazenam o escoamento têm capacidade de 100 Litros. Dentro das caixas foram colocados baldes graduados de 10 litros a fim de armazenar escoamento que não ultrapassem 10 litros.

A chuva foi aferida a cada hora por meio de um pluviômetro automático instalado na trilha. Seus dados foram confrontados com os de potenciais matriciais da água no solo, estes adquiridos por meio de sensores de umidade do solo atrelados a um datalogger, com aquisição dos dados de umidade a cada hora para a análise da drenagem da água no solo. Os sensores foram instalados ao longo da largura da trilha dentro das parcelas de erosão, para se entender os processos hidroerosivos da encosta que sofreu com o corte para material de empréstimo. Os sensores estão em profundidades diferentes: Parcela A (15 cm), Parcela B (15, 30 e $90 \mathrm{~cm})$ e Parcela C (15, 30 e $90 \mathrm{~cm})$ (Figura 3B).

Foram analisadas as propriedades granulométricas superficiais do solo da trilha e comparadas com as da floresta por meio da análise textural, feita em triplicata, seguindo o método da EMBRAPA (2011). As amostras foram coletadas, em ambos ambientes, no topo do solo a uma profundidade de $0-10 \mathrm{~cm}$. Também foi analisada a alteração das características físicas do topo do solo na trilha, portanto, foi elaborada análise granulométrica das partículas escoadas superficialmente no piso da trilha para relacionar com as porcentagens texturais presentes no solo in situ. Das amostras de escoamento, portanto, uma alíquota de um litro foi separada para análise em laboratório, essas foram secas na estufa para se obter as partículas que foram arrastadas superficialmente e para se calcular a porcentagem das frações granulométricas perdidas no piso da trilha. Foram utilizadas amostras de escoamento entre agosto de 2013 e dezembro de 2016 para as análises granulométricas, totalizando três anos e quatro meses de monitoramento. Cabe ressaltar que a classificação textural seguiu os parâmetros da United States Department of Agriculture (USDA, 2017). 

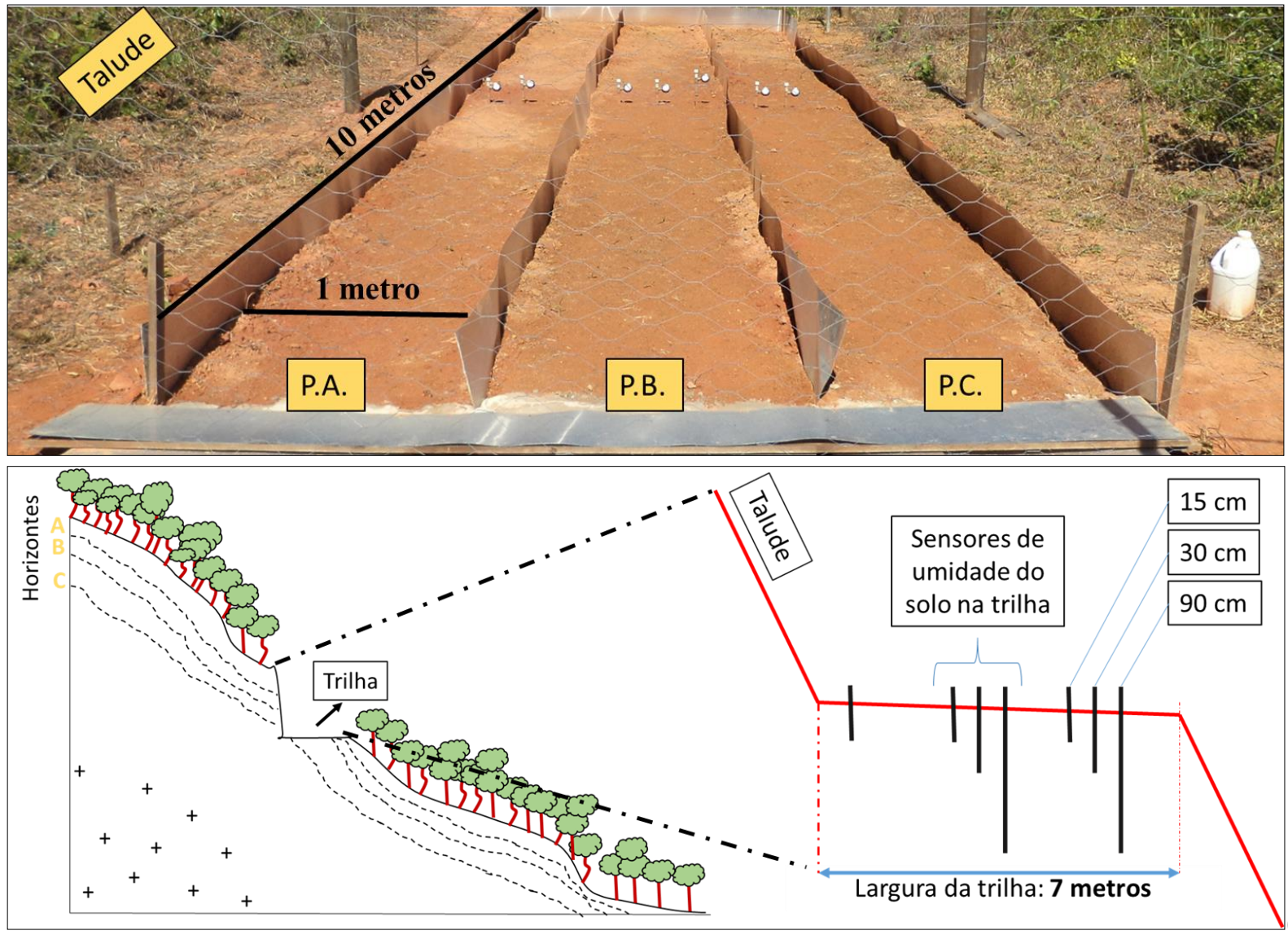

Figura 3 - Parcelas de erosão para mensuração do escoamento superficial (A); Ilustração da formação da trilha em encosta e esquema da instalação dos sensores de umidade do solo no piso da trilha (B). Organizado por Leonardo S.

Pereira (2017).

\section{Resultados e Discussões}

Observa-se que ao longo da largura da trilha a variabilidade do potencial pressão negativo apresenta distinção, mesmo em pronfundidades semelhantes. Comparando o potencial matricial da água no solo de $15 \mathrm{~cm}$ entre as parcelas de erosão que se encontram distribuidas na largura do piso da trilha, observa-se que a parcela A (P.A.) apresenta menor variação dos potenciais, salientando um solo nessa profundidade mais úmido. Analisando a mesma profundidade na parcela B (P.B.), constata-se maior variação do potencial negativo, salientando boa drenagem da água (Figura 4). Observa-se, portanto, que as duas profundidades estão apresentando comportamentos distintos, pois estão relacionados em um contexto complexo da encosta, estando posicionadas na trilha em pontos diferentes e, desse modo, apresentando comportamentos distintos, devido às influências hidrológicas das quais estão submetidas. Nesta 
perspectiva, P.A. encontra-se mais próximo do talude, recebendo com maior intensidade o volume da carga hidrológica do mesmo, o que culminou em um solo mais próximo à saturação.

Ao analisar $30 \mathrm{~cm}$ da P.B., observa-se que possui o mesmo comportamento da variação dos potenciais matriciais da água no solo de $15 \mathrm{~cm}$ de P.A., apresentando solo mais próximo à saturação em $30 \mathrm{~cm} \mathrm{e}$ mais seco e com maior variação em $15 \mathrm{~cm}$, alcançando taxas entre -100 e $-250 \mathrm{kPa}$ (Figura 4). Consequentemente, por P.B. apresentar em $15 \mathrm{~cm}$ maior drenagem da água para 30 e $90 \mathrm{~cm}$, observa-se que a água se movimenta lateralmente de $15 \mathrm{~cm}$ de P.A. para $30 \mathrm{~cm}$ de P.B. Observando a extremidade da trilha que é a parcela C (P.C.), ponto mais distante do talude, observa-se um solo mais próximo à saturação em $15 \mathrm{~cm}$, e em $30 \mathrm{~cm}$ solo com maior variação dos potenciais matriciais. Nessa perpectiva, observa-se que ao longo da largura da trilha o solo superficial $(15 \mathrm{~cm})$ fica próximo à saturação em suas extremidades e no meio da trilha ocorre maior variação dos potenciais matriciais. Contudo, no meio da trilha (Parcela B) em $30 \mathrm{~cm}$ ocorre o inverso, nessa profundidade o líquido é drenado de ambas as extremidades (Parcela A e C).

Em $90 \mathrm{~cm}$ a movimentação da água é mais linear, com pouca variabilidade do potencial matricial, e as parcelas B e C apresentaram comportamento semelhante nessa profundidade. Segundo Pereira \& Rodrigues (2013) a profundidade de $90 \mathrm{~cm}$ apresenta a menor tensão do solo, pois trata-se da zona de recarga. Contudo, $90 \mathrm{~cm}$ pode representar o mesmo horizonte de solo, apresentando semelhança de potencial matricial da água no solo. As profundidades mais superficiais podem estar inseridas em horizontes diferenciados, devido ao corte de encosta para a formação da trilha, modificando a morfologia original do relevo e alterando sua dinâmica hidrológica.

Analisando o escoamento superficial no período analisado (27 de julho até 28 de agosto de 2016), observa-se quatro dias de ocorrência de escoamento, este estando associado com solos próximos à saturação em todas as profundidades. As parcelas apresentaram acumulado de escoamento diferenciadas em todos os dias de ocorrência de escoamento. A Parcela A no dia 07 de agosto obteve escoamento de 10 $\mathrm{mm}$, com acumulado de chuva diário de 22,6 mm (Figura 4). Em contrapartida, a parcela B obteve escoamento de $7 \mathrm{~mm}$ e a parcela $\mathrm{C}$ de $3 \mathrm{~mm}$, seguindo esse mesmo padrão nos demais dias de escoamento. A parcela A deve estar recebendo com maior intensidade a carga hidrológica do talude, já que está mais próxima, e essa influência vai diminuindo ao passo que ocorre distanciamento do talude, culminando na menor formação de escoamento na extremidade da trilha (P.C.), em detrimento as parcelas P.A. e P.B. 

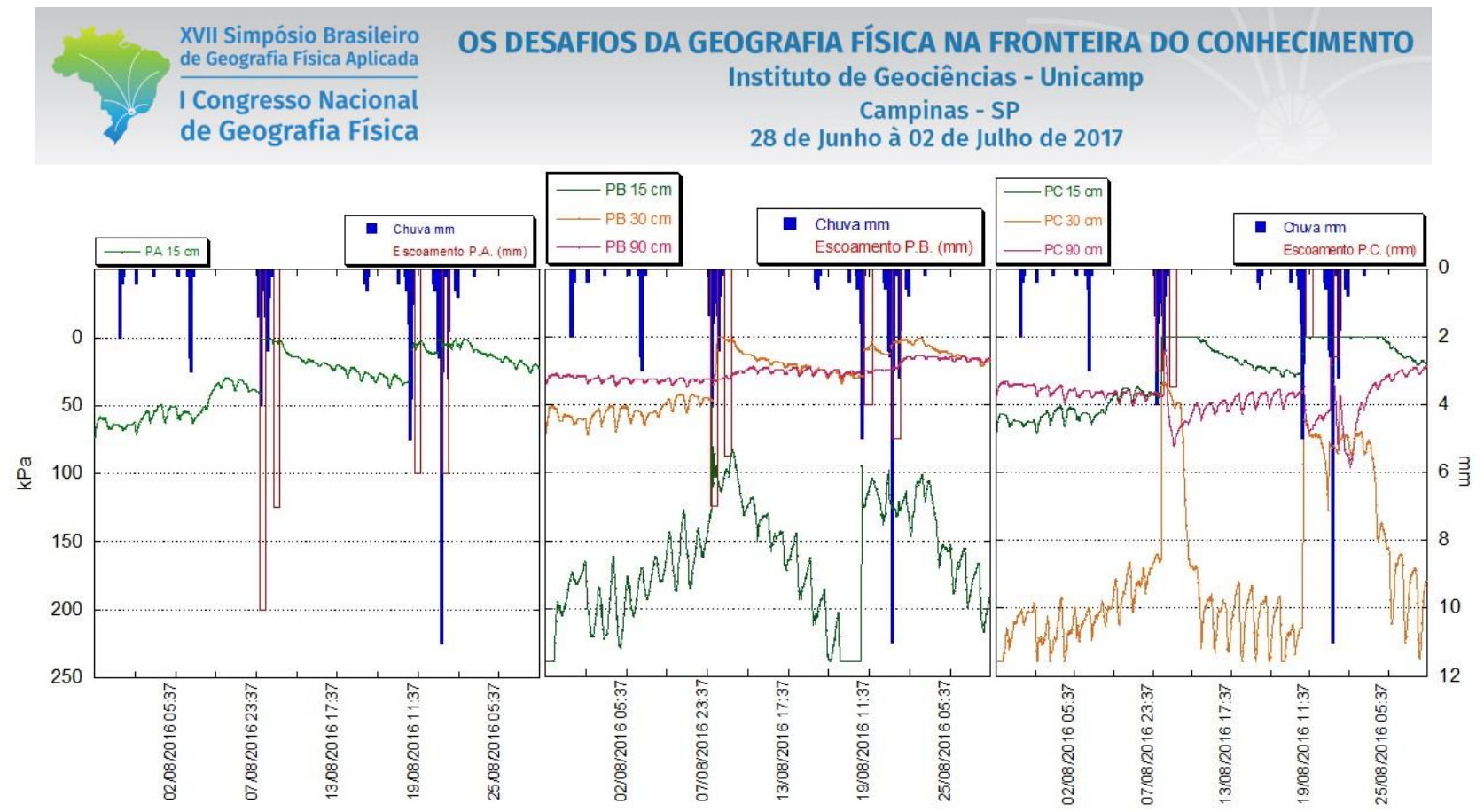

Figura 4 - Potenciais matriciais da água no solo em cada parcela por profundidade $(15,30$ e $90 \mathrm{~cm})$ associados com a chuva e o escoamento superficial.

$\mathrm{Na}$ análise textural, ambos os ambientes possuem características de suas propriedades semelhantes, sendo classificados como Franco-argilo-arenosos, onde a área de floresta possui 39,4\% de areia grossa, 11,3\% de areia fina, $23,2 \%$ de silte e $26,2 \%$ de argila e a área de trilha possui $38,4 \%, 8,8 \%, 17,9 \%$ e 34,8 , respectivamente (Figura 5A).

Nessa perspectiva, as frações com maior potencialidade à erosão são as frações areia e silte, sobretudo, areia fina, pois não possuem alta capacidade de agregação, o inverso com a argila, que é a fração mais difícil de remoção, pois possui maior capacidade de agregação, devido a sua maior superfície de contato (MORGAN, 2005). Ao analisar o tamanho das partículas transportadas superficialmente pelo escoamento, constatam-se taxas majoritárias de silte $(50,6 \%)$, seguido de argila $(31,6 \%)$, areia fina $(11,5 \%)$ e grossa $(6,3 \%)$ (Figura 5B). Observa-se que o silte está sendo transportado 32,7\% mais do que as suas taxas originais no solo, bem como a argila que está sendo transportado $31,6 \%$, próximo a sua taxa original do solo in situ. Observa-se que as partículas menores, mesmo demonstrando grande concentração no solo, importantes para a resistência dos agregados, especialmente a argila devido a maior superfície de contato, estão mais susceptíveis à erosão e transporte, isso devido à baixa capacidade de ligação iônica que estas partículas perderam devido ao constante processo de lixiviação que esse solo está sofrendo, carregando junto as bases do solo.

A perda dessas frações granulométricas, essenciais para ajudar no processo de recuperação da vegetação do solo devido a maior capacidade de troca catiônica e aniônica, está corroborando para a intensificação de um solo degradado e incipiente, dificultando o seu processo de recuperação. 

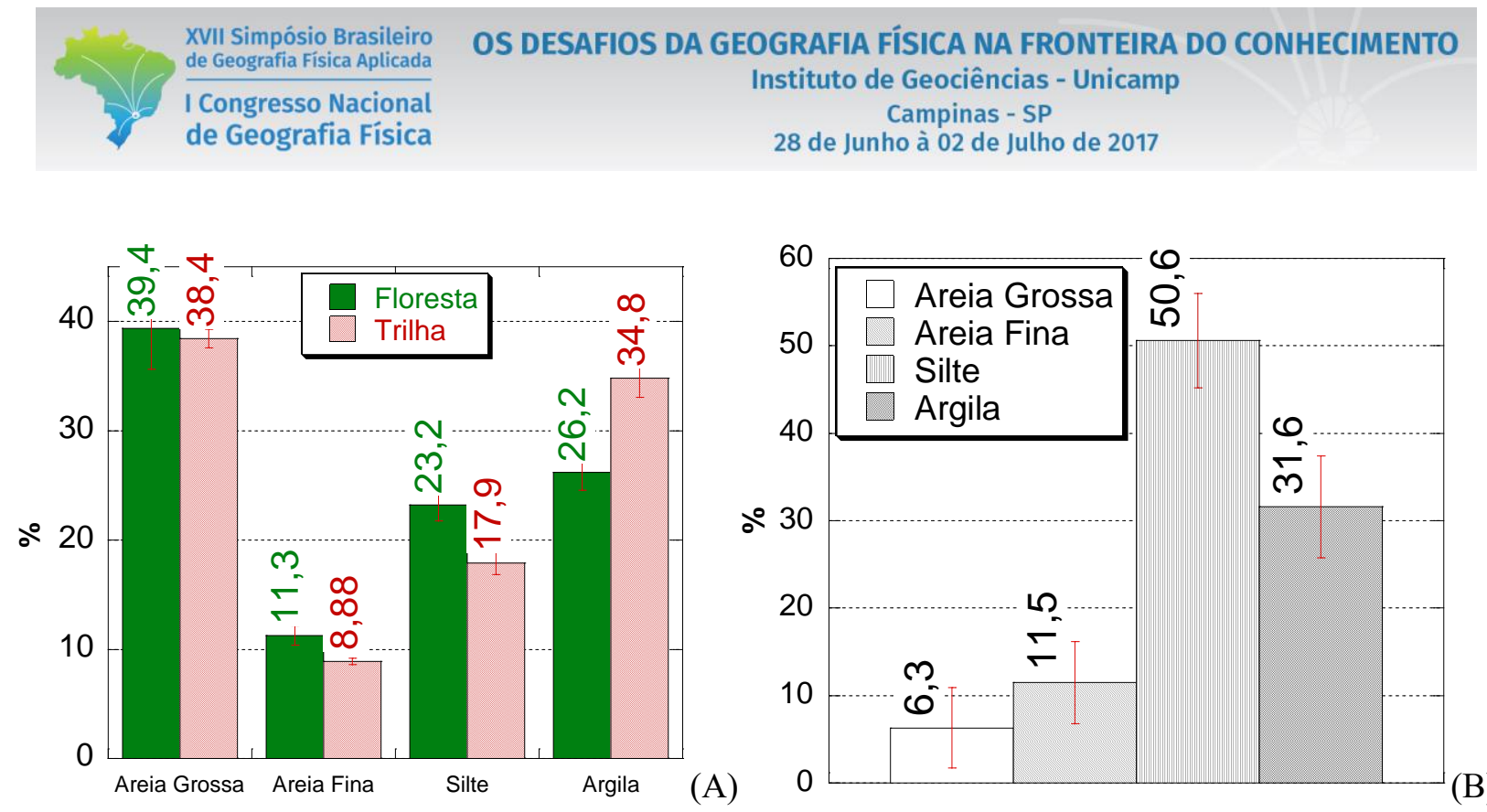

Figura 5 - Análise textural do solo da trilha e floresta (A); análise da granulometria das partículas de solo escoadas superficialmente (B).

\section{Conclusões}

A análise de trilha em encosta deve estar pautada em um discurso geomorfológico, considerando as variáveis que influenciam a dinâmica de uma bacia hidrográfica como a análise dos solos, a hidrologia, chuva, vegetação, relevo, geologia, pois interferem diretamente na funcionalidade da trilha.

O piso da trilha pode apresentar diferença nos horizontes do solo, já que a sua formação se deu por meio de um corte de encosta, alterando a sua dinâmica hidrológica original, culminando na movimentação da água e no processo de formação de escoamento de modo distinto ao longo de sua largura, como constatado, segundo a metodologia aplicada.

O talude pode estar influenciando na maior formação de escoamento superficial na parcela $\mathrm{A}$, situada próxima ao talude, devido à descarga hidrológica nessa área, bem como influenciando na movimentação da água no solo por meio da drenagem da água que sai do talude para a trilha.

O processo de escoamento da água está arrastando com maior intensidade silte e argila, esta, que é importante para a agregação do solo e essenciais para a ajudar no processo de recuperação da vegetação devido a maior capacidade de troca catiônica e aniônica, corroborando para a intensificação de um solo degradado e incipiente, culminando para uma trilha degradada e de difícil percurso devido aos problemas de erosão. 


\section{Agradecimentos}

Agradecemos à Capes e ao CNPq pelo apoio financeiro. Ao técnico de aferição da estação experimental, Sebastião Jorge de Oliveira, assim como agradecemos à Yoriko Kamiyama (Dona Annie), empresária da Agroindústria Y. Kamiyama Alimentos (Sítio Recanto da Paz/Gengibre de Ubatuba), cedendo espaço para a instalação da estação experimental.

\section{Bibliografia}

BUZATO, E. Avaliação de impactos ambientais no município de Ubatuba: uma proposta a partir dos geoindicadores. Tese (doutorado) - Universidade de São Paulo, 2012.

EMBRAPA. Centro Nacional de Pesquisa de Solos (Rio de Janeiro, RJ). Manual de métodos de análise de solo / Centro Nacional de Pesquisa de Solos - 2. ed. Ver. Atual. - Rio de Janeiro, 2011.

FERNANDES, J. Percepção ambiental: as transformações no cotidiano de caiçaras de Ubatuba - SP na década de 1960 e na primeira década do século XXI. Dissertação (mestrado) - Universidade de Taubaté, Programa de Pós-Graduação em Ciências Ambientais, 2009.

FIGUEIREDO, M. A.; FILHO, R. E. F.; VARAJÃO, A. F. D. C.. Soil Quality as Geoindicator to Trail Assessment of the Parque Nacional da Serra do Cipó, MG, Brazil. Anuário de Geociências - UFRJ. Vol. 35 - 1. p. 199-208. 2012.

GUERRA, A. J. T. Experimentos e Monitoramentos em Erosão dos Solos. Revista do Departamento de Geografia da UFRJ, 16, 32-37. Rio de Janeiro/ RJ, 2005.

JORGE, M. C. O.; GUERRA, A. J. T.. Geodiversidade, Geoturismo e Geoconservação: Conceitos, Teorias e Métodos. Espaço Aberto (UFRJ), v. 6, p. 151-174, 2016.

JORGE, M. C. O.; GUERRA, A.J.T.; FULLEN, M. A.. Geotourism, Geodiversity and Geoconservation in Ubatuba Municipality, São Paulo State, Brazil. Geography Review, v. 29, p. 2329, 2016.

JORGE, M.C.O.; PEREIRA, L. S.; GUERRA, A. J. T.; MOREIRA, R.. Potencial Geoturístico Em Unidades De Conservação: Um Estudo Da Trilha Cachoeira Da Água Branca Situada No Parque Estadual Da Serra Do Mar, Município De Ubatuba-Sp. Revista Geonorte, v. 10, p. 458-465, 2014.

KROEFF, L. L. Contribuição metodológica ao planejamento de trilhas ecoturísticas no parque nacional da Serra dos Órgãos (Parnaso, RJ). Dissertação de Mestrado, Programa de Pós-Graduação em Geografia da Universidade Federal do Rio de Janeiro, 2010.

MORGAN, R. P. C. Soil Erosion and Conservation. England: Blackwell, 2005.

NUNES, L.H. Jornal Maranduba News. Ano I, edição 12. Agosto de 2010. Disponível em <http://issuu.com/maranduba/docs/jornalmarandubanews12web/6>. Data: 10/01/2015.

PEREIRA, L. S.; JORGE, M.C.O.; RODRIGUES, A. M.; GUERRA, A.J.T. Contribuição das chuvas de baixa intensidade nos processos erosivos superficiais em ambiente degradado bacia hidrográfica do rio Maranduba, Ubatuba/SP. Revista Equador (UFPI), Vol. 4, No 3, 2015. 


\section{OS DESAFIOS DA GEOGRAFIA FÍSICA NA FRONTEIRA DO CONHECIMENTO \\ Instituto de Geociências - Unicamp \\ Campinas - SP \\ 28 de Junho à 02 de Julho de 2017}

PEREIRA, L. S.; RODRIGUES, A. M.; JORGE, M. C. O.; GUERRA, A. J. T.; FULLEN, M. A.. HydroErosive Processes In Degraded Soils On Gentle Slope. Revista Brasileira de Geomorfologia. v. 17, nº 2. 2016.

PEREIRA, L. S.; RODRIGUES, A. Sistemas de Manejo de Cultivo Mínimo e Convencional: Análise Temporal da Dinâmica Hidrológica do Solo e da Variação Produtiva em Ambiente Serrano. Revista Brasileira de Geografia Física. Volume 6, número 6. 2013.

RANGEL, L. A.; GUERRA, A. J. T.. Degradação de trilhas na Reserva Ecológica da Juatinga em Paraty - Rio de Janeiro. Rev. Ambient. Água vol. 9 n. 4 Taubaté. 2014.

ROSEGHINI, W. F. Ocorrência de eventos climáticos extremos e sua repercussão sócioambiental no litoral norte paulista. Dissertação (mestrado) - Universidade Estadual Paulista, Faculdade de Ciências e Tecnologia. Presidente Prudente, 2007.

SAFARI, A.; KAVIAN, A.; PARSAKHOO, A.; SALEH, I; JORDÁN, A.. Impact of different parts of skid trails on runoff and soil erosion in the Hyrcanian forest (northern Iran). Geoderma, Volume 263, Pages 161-167. 2016.

SANTOS, D. D.; GALVANI, E. Seasonal and time distribution of rainfall in Caraguatatuba-SP and extreme events occurring in the years 2007 to 2011. Ciência e Natureza, Santa Maria, V. 36, n², 214229, 2014.

USDA (United States Department $\quad$ of Agriculture). http://www.nrcs.usda.gov/wps/portal/nrcs/detail/soils/survey/?cid=nrcs142p2_054167. Acesso em $07 / 02 / 2017$. 